Subjects and Methods In this study, 409 public assistance recipients with illness/disabilities and 787 controls were recruited. One or two controls were matched with each recipient on age (10-year category) and residence area (city, town or village). A self-administered and anonymous questionnaire was distributed by case workers and local welfare commissioners to public assistance recipients and control subjects, respectively, during the period from July to November 2007. The information on birth weight, parent-child relationship in childhood, relationship with friends, academic backgrounds for both study subjects and their parents, marital history, lifestyles including smoking and alcohol drinking habits, health action, employment history, possession of driver's license, and relationship with their children.

Results and Discussion In addition to the reported common characteristics, higher frequencies of poor relationship with their parents, smokers, no driver's license, and poor relationship with their children were observed in the public assistance recipients than control subjects. Interactions between each factor and more details will be discussed.

\section{SP5-25 ASSESSMENT OF BEHAVIOURAL ANTECEDENTS TO TESTICULAR SELF-EXAMINATION AND TORSION AMONG MALE STUDENTS OF BABCOCK UNIVERSITY ILISAN-REMO, OGUN STATE, NIGERIA}

doi:10.1136/jech.2011.142976p.61

0 Solademi, ${ }^{*}$ F Oshiname. University of Ibadan, Ibadan/Oyo State, Nigeria

Testicular Torsion (TT) poses a serious health challenge to young men and Testicular Self-Examination (TSE) is recommended for its early detection and management. However studies related to the perception and adoption of TSE among students are not common in Nigeria. This study was designed to assess the knowledge, perceptions and practice of TSE, using a three-stage random sampling technique in selecting 500 male undergradutes for the quantitative survey. Respondents' mean age was $21 \pm 3.2$ years. Only $28.2 \%$ had heard about TT; while $39.6 \%$, had heard about TSE. The sources of information about TSE included health workers (16.4\%), books (12.0\%), magazines (10.6\%), and friends (9.4\%). Respondents' mean knowledge score was $8.5 \pm 4.8$. $58 \%$ perceived every male to be vulnerable to testicular pain and/or swelling. Majority $(62.0 \%)$ perceived testicular pain to be a symptom of testicular disorder, while $67.6 \%$ believed that swelling in the testes requires medical care. Few (18.2\%) knew that testicular pain and/or swelling could lead to loss of testes. $67 \%$ considered TSE to be a useful practice. Only $0.4 \%$ had ever had TT; $33.0 \%$ had ever experienced testicular pain and/or swelling and only $8.4 \%$ had ever visited a hospital immediately. Only $48.0 \%$ had ever practised TSE. The mean knowledge score of respondents who had ever practised TSE $(10.6 \pm 5.1)$ was significantly higher than the score of those who had never done so $(6.7 \pm 3.7)(p<0.05)$. Participants' knowledge of TT and TSE was also low. Integration of TSE into the general studies curriculum of the university.

\section{SP5-26 DETECTION OF GOAT MILK ADULTERATIONS IN BRAZIL: A PUBLIC HEALTH QUESTION}

doi:10.1136/jech.2011.142976p.62

1' M Paiva, ${ }^{1}$ M A M Furtado, ${ }^{2} \mathrm{~K}$ M Paiva. ${ }^{*}$ Federal University of Juiz de Fora, Juiz de Fora, Minas Gerais, Brazil; ${ }^{2}$ University of São Paulo, São Paulo, Brazil

Introduction Goat milk and their dairy products are frequently adulterated with cow milk because of its smaller production in the world and its higher price compared to cow milk. However, the main benefit claimed about goat milk is that it is less allergenic than cow milk and is a suitable substitute, especially among children. Besides, cow milk proteins, even in low concentrations, are able to trigger allergic reactions.

Methods It was collected reliable samples of goat and cow milk. Afterwards, adulterations were performed adding different concentrations of cow milk ( $3 \%, 5 \%, 8 \%, 10 \%, 12 \%, 15 \%$ and $50 \%)$ in goat milk. Polyacrylamide gel electrophoresis (UREA-PAGE) and densitometry (ImageQuant TL) were used because this technique is simple and inexpensive to analyse proteins. Samples were applied in duplicate, obtaining two densitograms for each concentration. It was used bovine $\alpha_{\mathrm{s} 1}$-casein to detect cow milk, because this protein fraction has a larger electrophoretic migration than caprine $\alpha_{\mathrm{s} 1}$-casein.

Results Area peak of bovine $\alpha_{\mathrm{s} 1}$-casein were directly proportional to the increase of concentration of cow milk and a linear regression was performed with the average of the duplicates: $y=56.18 x+1239$. The linearity of the method could be observed because of high correlation $\left(\mathrm{R}^{2}=0.9989\right)$.

Conclusion There is no official method to assure the absence of cow milk in goat milk and their dairy products in Brazilian legislation. Then this method can be easily introduced as a tool to detect this fraud, which may represent a dangerous for health population.

\section{SP5-27 PERCEPTION OF PAKISTANI WOMEN PILLION RIDERS ABOUT HELMET USE: A QUALITATIVE STUDY}

doi:10.1136/jech.2011.142976p.63

U Khan, ${ }^{*}$ N Zia, S Awan, A Khan. Aga Khan University, Karachi, Pakistan

Introduction Despite the importance of helmet in prevention of head injuries in motorcyclists, there is lack of use of helmet both by riders and pillion passengers. It is a common practice in Pakistan that women pillion passengers do not wear helmet. The objective of the study is to assess the knowledge of women pillion riders regarding the motorcycle safety especially use of helmets.

Methods Data were collected from five focus group discussions held with women pillion riders working at the Aga Khan University. The study participants were recruited voluntarily. Written informed consent was taken from each participant before beginning of each discussion.

Results Some major themes emerged from the data analyses, which included (1) motorcycle is a risky transport particularly due to clothing of women that gets trapped in wheels and causes injuries (2) All participants never wore a helmet and never thought about it before, on the contrast, the most important benefit of helmet use expressed was "safety" (3) Main barriers to helmet use, identified were, included: lack of appropriate information on helmet use; unaware of helmet laws; gazes or stares of people; the current sitting style of women in bikes with both the legs on one side (4) Strategies to implement helmet use included; awareness campaigns in media; women should make example and start using helmet as a first step; strict law enforcement in the form of fine/challans.

Conclusion The findings of this study provide insight factors associated with non-use of bicycle helmets.

\section{SP5-28 COST OF DOMICILIARY TREATMENT OF DRINKING WATER IN SELECTED SLUMS IN NORTH INDIA}

doi:10.1136/jech.2011.142976p.64

Ritvik, * S Kapoor, C Pandav, A Krishnan. All India Institute of Medical Sciences, New Delhi, India

Introduction Treatment of drinking water at home is commonly advocated for prevention of diarrhoea by health personnel. The methods of disinfection include chlorination, boiling or use of filters. Among others, the cost of water treatment is a known barrier to its practice. 